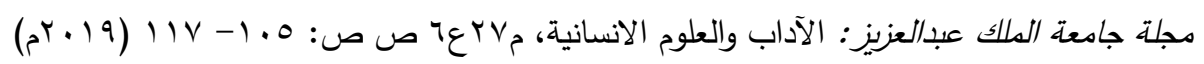
DOI:10.4197/Art.27-6.7

\title{
أثر قاعدة سد الذرائع في زواج المسيار
}

\author{
رؤى بنت طلال بن عبد الرحمن محجوب \\ $1 \leq \ldots \vee \wedge 1 \wedge$ \\ (قسم الثريعة والدراسات الإسلامية - تخصص أصول الفقه) \\ كلية الآداب والعلوم الإنسانية \\ جامعة الملك عبد العزيز \\ جلة - المدلكة العربية السعودية
}

مستخلص. بسم الله والحمد لله والصلاة والسلام عل رسول الله أما بعد: لما كان تخريج الفروع على الأصول له

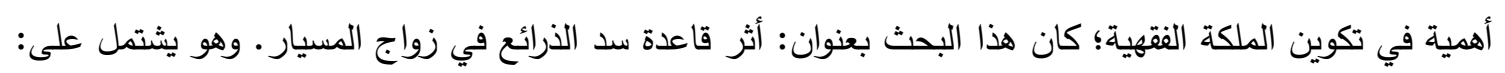

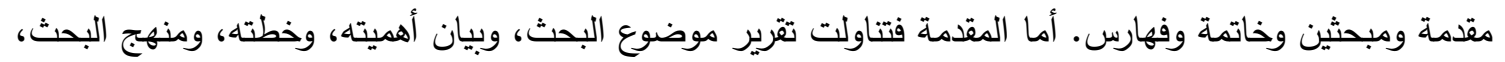

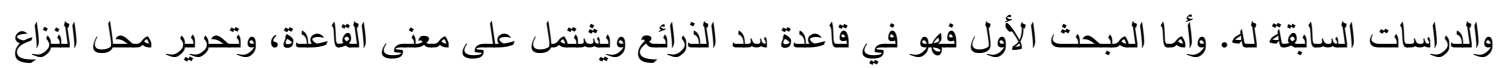

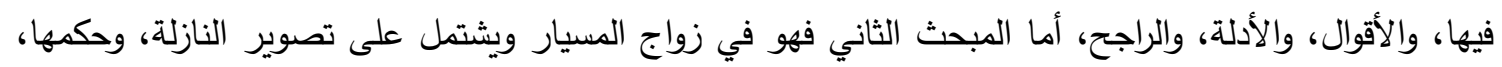
وأثر قاعدة سد الذرائع على زواج المسيار ـ أما الخاتمة فتتضمن أهم النتائج والتوصيات.

الفقهاء في فهم نصوص الكتاب والسنة واستخراج

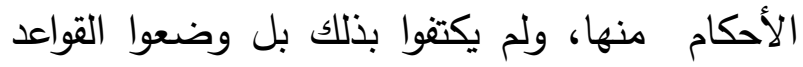

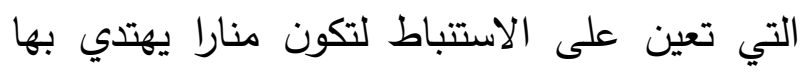
العلماء، فخلفوا ثروة ضخمة في علم الأصول

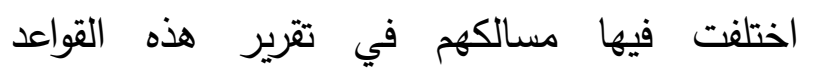

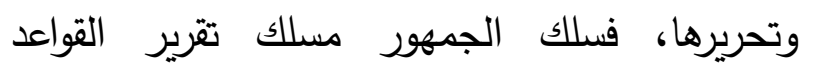
الأصولية على مقتضى الأدلة العقلية والنقلية دون التفات إلى الفروع الفقهية، وسلك الحنفية مسلك الكية

\section{المقدمة}

الحمد الله والصلاة والسلام على رسول الله وعلى آله وصحبه ومن والاه، أما بعد: فلم يزل كتاب الله تعالى وسنة رسوله صلى صلى الله عليه وسلم معينا لا ينضب لهداية البشر وصلاح أمر ولئل

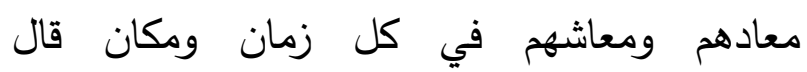

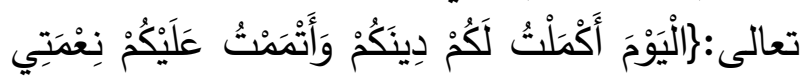

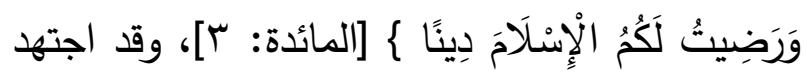


الفهارس ويحتوي على قائمة المراجع، وفهرس الموضوعات.

منهج البحث: اتبعت في كتابة البحث المنهج الآتي: أولا: ما يتعلق بالقاعدة الأصولية: ذكر معنى

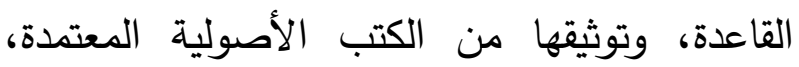
وتحرير محل النزاع فيها، ثم ذكر الأقوال المشهورة فيها، وذكر أدلة كل قول مع بيان الراجح من

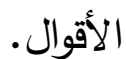

ثانيا: ما يتعلق ببيان أثر القاعدة في زواج المسيار: تصوير النازلة، بيان حكم المسألة مع ذكر لايلي

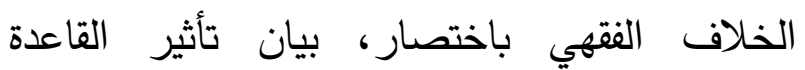
الأصولية على النازلة الفقهية، وعدم الإسهاب في الأدلة الأخرى إذ ليست هي مقصود البحث. ثالثا: السير على المنهج العلمي وذلك بعزو الآيات القرآنية إلى سورها بذكر اسم السورة ورقم الآية،

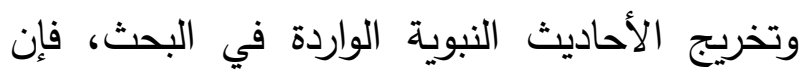
كان الحديث في الصحيحين أو أحدهما أكتفي بالعزو

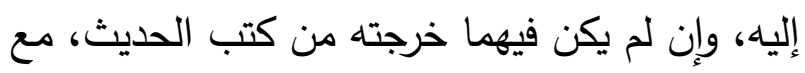
نقل ما حكم أهل العلم على الحديث صحة وضعفاً، والرجوع إلى المصادر العلمية في البحث. الاراسات السابقة: ظهرت العديد من الكتابات والبحوث حول تخريج الفروع على الأصول فمن هذه البحوث: القواعد الاصولية المؤثرة في نوازل الاطعمة و الاشربة و اللباس و الزينة: جمعا و دراسة، لفرقاط

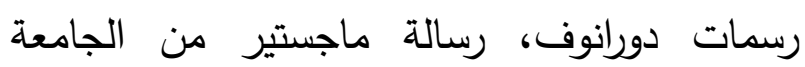
الإسلامية، والقواعد الاصولية المؤثرة في النوازل

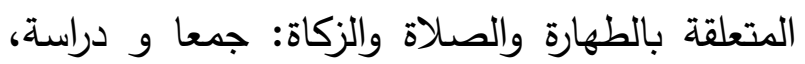
لتوري لاسينا، رسالة ماجستير من الجامعة ولهاه الإسلامية، القواعد الأصولية المؤثرة في النوازل
تقرير القواعد على مقتضى ما نقل من أئمتهم من

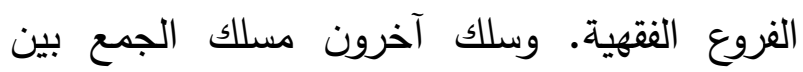
حسنى الطريقتين بأخذ الأصول وبناء الفروع عليها ليخرجوا بعلم أصول الفقه من نطاق البحث النظري إلى الواقع العملي التطبيقي. ومما لا شك فيه أن ربط القواعد الأصولية بالنوازل المعاصرة يحقق ثمرة علم الأصول، من أجل ذلك كان هذا البحث (أثر قاعدة سد الذرائع في زواج المسيار ). أهمية الموضوع:

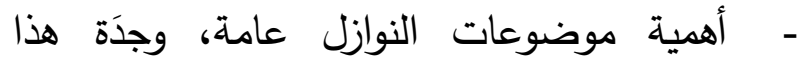
الموضوع خاصة حيث أنه يتعلق بدراسة زواج

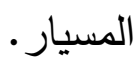
- تمية الملكة الفقهية عند الباحث عن طريق معرفة مناهج العلماء في الاستنباط، ومآخذهم في

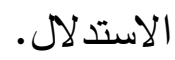
- تأكيد شمولية الشريعة الإسلامية وصلاحيتها لكل زمان ومكان من خلال بحث أحكام النوازل. خطة البحث: يشتمل البحث على مقدمة، ومبحثين، وخاتمة، وفهارس. المقدمة: تتاولت تقرير موضوع البحث، وبيان أهميته، وخطته، ومنهج البحث، والدراسات السابقة .4 المبحث الأول: قاعدة سد الذرائع ويشتمل على مطالب تحتوي ما يلي: معنى القاعدة، وتحرير محل النزاع، والأقوال، والأدلة، والراجح.

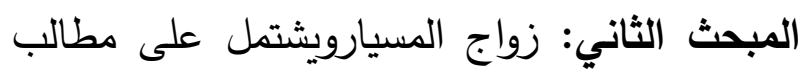
تحتوي ما يلي: تصوير النازلة، وحكم المسألة، وأثر قاعدة سد الذرائع على زواج المسيار • الخاتمة: وستتضمن أهم النتائج والتوصيات. وأخيراً 
ثالثا: ما كان إفضاؤه إلى المفسدة ظنا، وهذه اختلف فيها '. رابعا: ما كان مفسدته كثيرا لا غالبا ولا نادرا، واختلف فيها كما يلي. المطلب الثالث: الأقوال: اختلف الفقهاء في الأخذ بسد الذرائع كأصل من أصول الاستدلال إلى أقوال وهي كما يلي: القول الأول: قول المالكية `، والحنابلة ^، اعتبروالئية سد الذرائع أصل من أصول الاستدلال وحجة يعمل بها. القول الثاني: قول الثافعية، اختلف في تحديد موقف الإمام الشافعي رحمه الله وسبب ذلك أنه في مواطن ذكر أنه يأخذ بسد الذرائع ، وفي مواطن

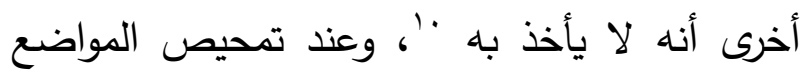
التي اختلف فيها القول عن الإمام الثافعي رحمه الله، نجد أنه أعمل قاعدة سد الذرائع في مجال ضيق ولم يتوسع في الأخذ بها'". القول الثالث: قول الحنفية وهو أنهم لم يصرحوا في أصول مذهبهم باعتبار سد الذرائع أصلا من أصول

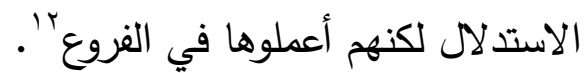

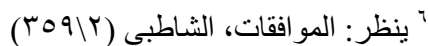

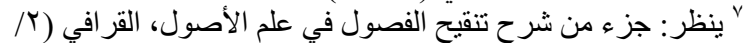

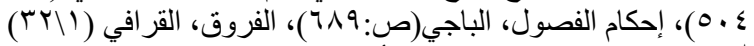

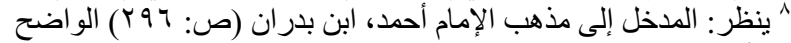

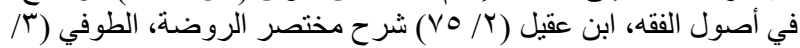

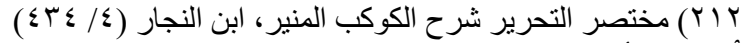

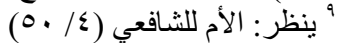

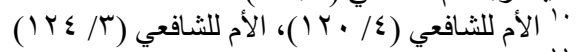

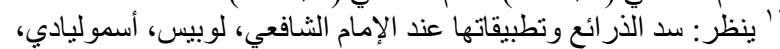

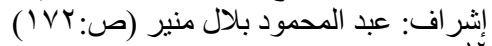

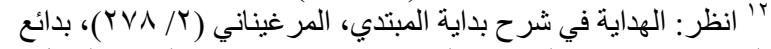

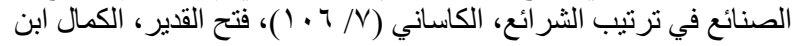

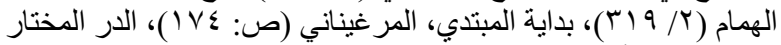

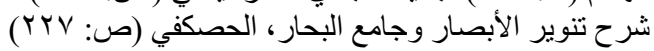

المتعلقة بالصيام و الحج، لإبراهيم تيجان إبراهيم جكيتي، رسالة ماجستير من الجامعة الإسلامية. ولم أجد فيما ظهر لي بحث يتعلق بأثر قاعدة سد الذرائع

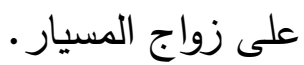
وأخيراً، أسأل الله التوفيق والسداد، وصلى الله على نبينا محمد وعلى آله وأصحابه وسلم تسليماً كثيراً. المبحث الأول: قاعدة سد الأرائع المطلب الأول: معنى القاعدة: السد لغة: السين والدال أصل واحد يدل على ردم الثيء وملاعمته وإغلاق الخلل، من سددت الثلمة سدا، ويأتي بمعنى الحجز فكل حاجز بين الثيئين سدا، ويأتي بمعنى المنع يقال: سد عليه باب الكلام أي: منعه منه' . والمعنى الذي يقصد هنا هو المنع.

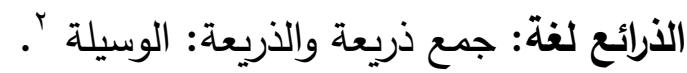

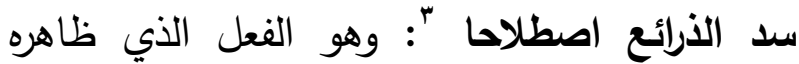
مباح ويتوصل باه إلى فعل المحرم. المطلب الثاني: تحرير محل النزاع: يتبين موضع الخلاف من خلال بيان أقسام الذرائع وهي كما يلي: أولا: ما كان إفضاؤه إلى المفسدة قطعيا، وهذه تسد باتفاق ؛ ثانيا : ما كان إفضاؤه إلى المفسدة نادرا، وهذه لاتسد • باتفاق

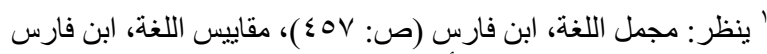

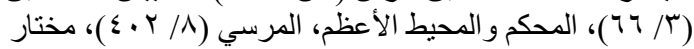

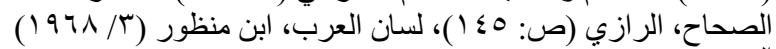

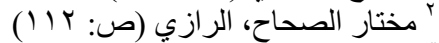

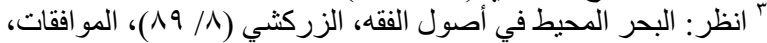

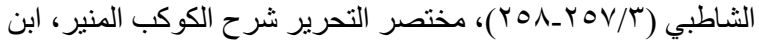

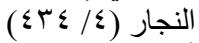

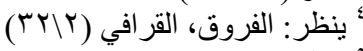

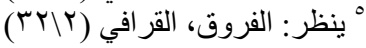




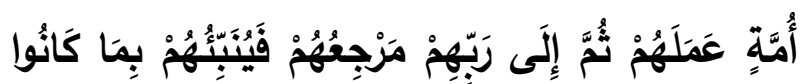

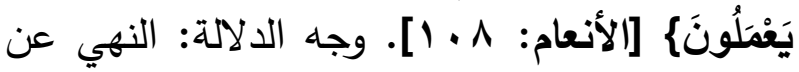
سب آلهة المشركين وهو جائز لأنه ذريعة لسب الأعادي

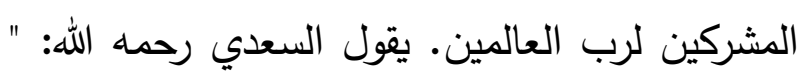
وفي هذه الآية الكريمة، دليل للقاعدة الثرعية وهو أن الوسائل تعتبر بالأمور التي توصل الإليها، دائل وأن

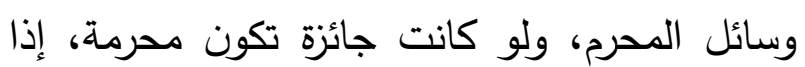

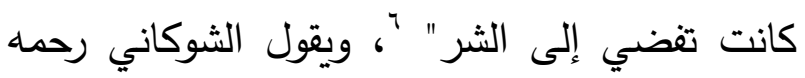
الله: " الآية أصل أصيل في سد الذرائع" ل.

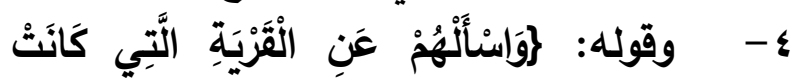

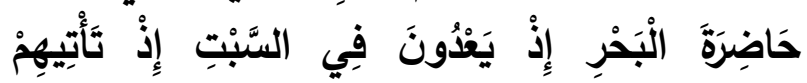

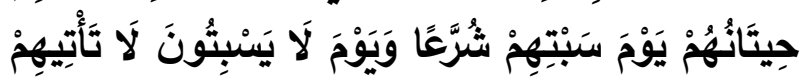

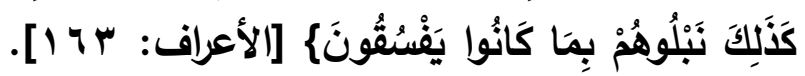
وجه الدلالة: قال ابن العربي رحمه الله: "هذه الآية

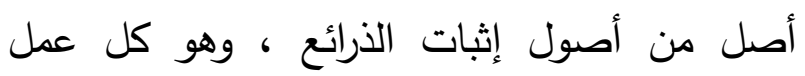

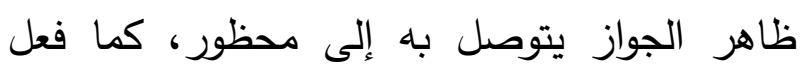

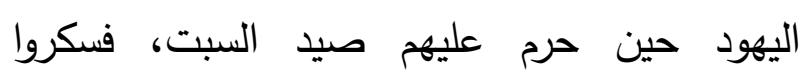
الأنهار ، وربطوا الحيتان فيه إلى يوم الأحد" ^.

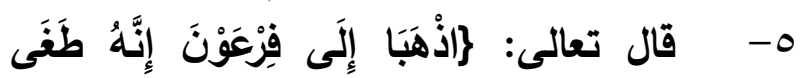

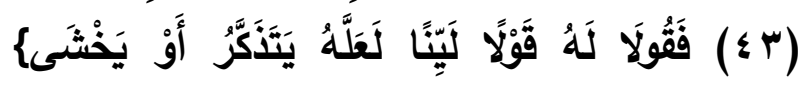

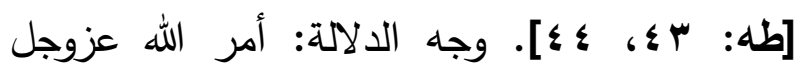
موسى وهارون عليهما السلام أن يقولا لفرعون كلاما لطيفا سهلا ليس فيه ما يغضب؛ لئلا يكون ذريعة - لتنفيره

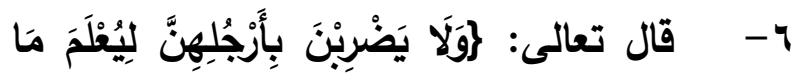

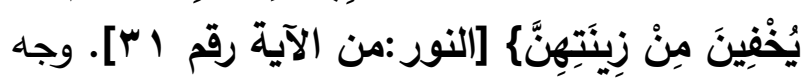

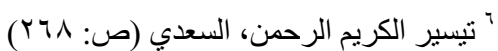

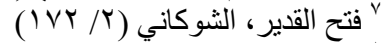

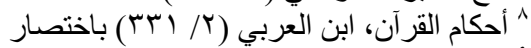

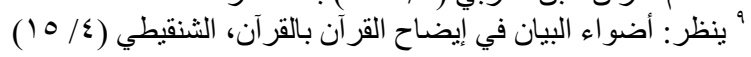

القول الرابع: قول الظاهرية: لم يأخذوا بسد الذرائع' .

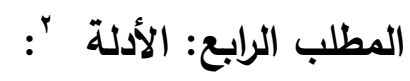
أدلة القول الأول: استدل الألة القائلون باعتبار سد الأرائع بأدلة منها: - الأول الأدلة من القرآن:

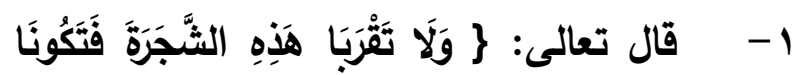

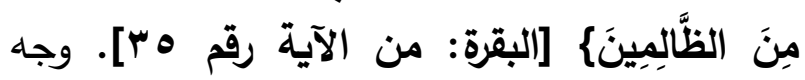

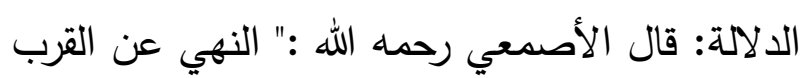

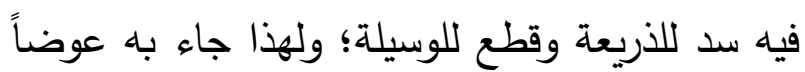

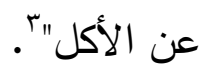

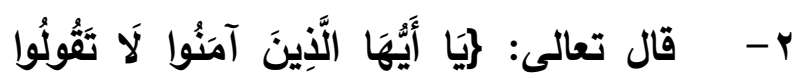

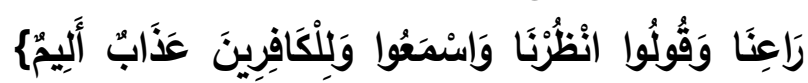

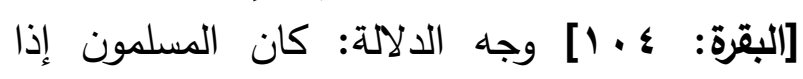
خاطبوا الرسول صلى الله عليه وسلم إذا علمهح شيئا في الدين يقولون له راعنا يقصدون بذلك مراعاتهم،

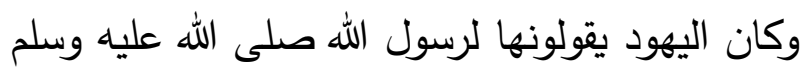

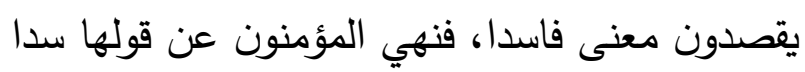

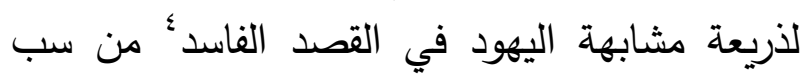

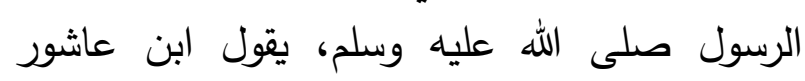

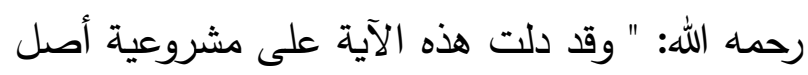

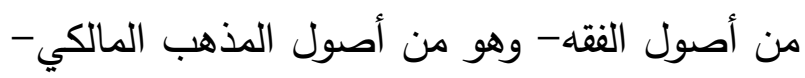

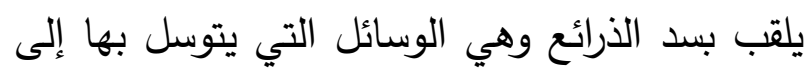
أمر محظور" ".

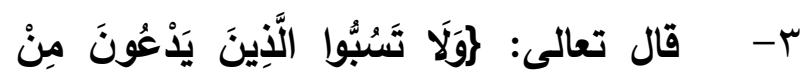

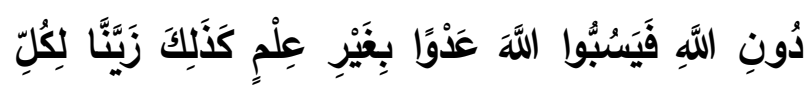

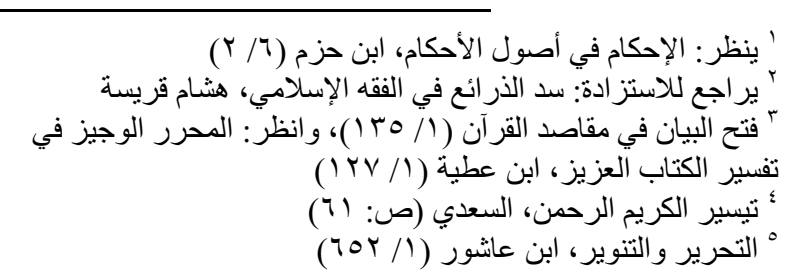


إذا فعلتن ذلك قطعتن أرحامككن". وجه الدلالة: نهى الرسول صلى الله عليه وسلم عن الجمع بين المرأة

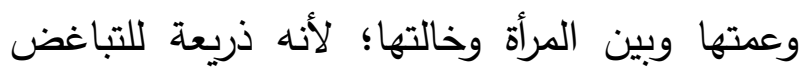

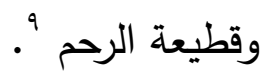
ـ - أنه أثير على النبي صلى الله عليه وسلم بقتل من ظهر نفاقه فقال: " أخاف أن يقول الناس:

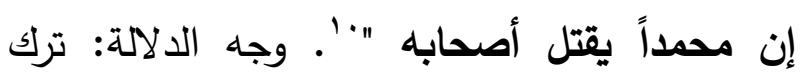
النبي صلى الله عليه وسلم قتل المنافقين؛ طلبا للتاليف ولئلا يكون ذريعة للتنفيرعن الإسلام ".

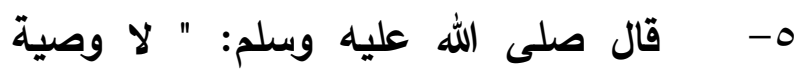
لوارث"' أ. وجه الدلالة: نهى الرسول صلى الله عليه

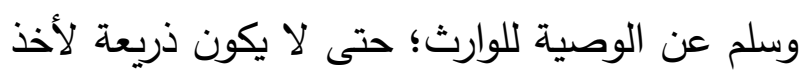

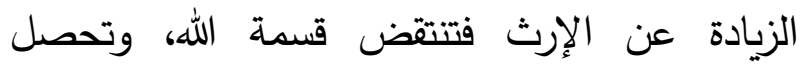

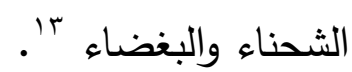

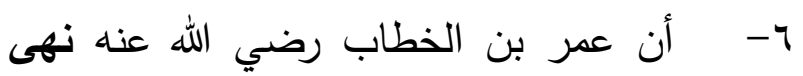
عن الصلاة تحت شجرة بيعة الرضوان، ثم قطعها

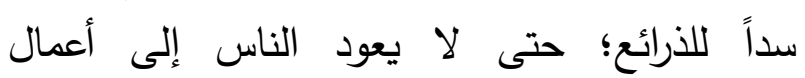

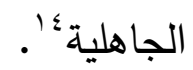

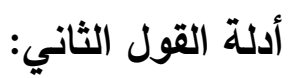
استدل القائلون بعدم اعتبار سد الذرائع بأدلة منها:

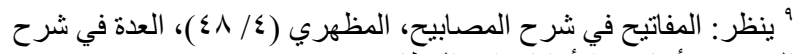

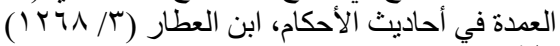

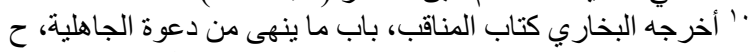

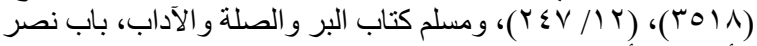

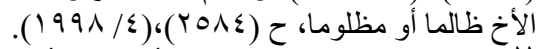

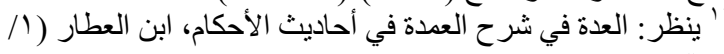
(ror

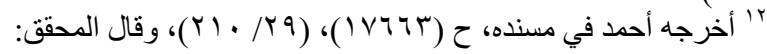

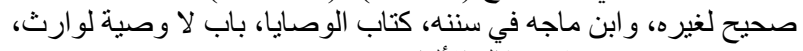

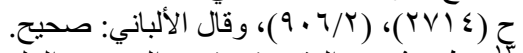

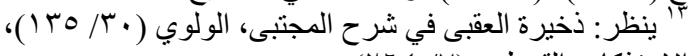

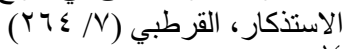

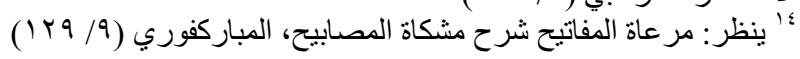

الدلالة: نهي الله المرأة من الضرب برجلها لإسماع

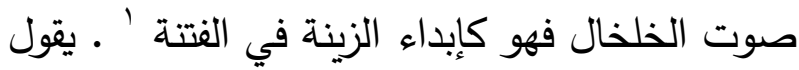
السعدي رحمه الله: "ويؤخذ من هذا ونحوه، قاعدة سد الوسائل، وأن الأمر إذا كان مباحا، ولكنه يفضي إلى هنى وندوه

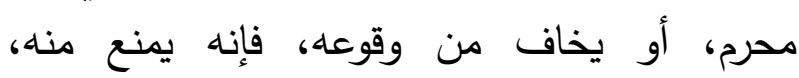
فالضرب بالرجل في الأرض، الأصل أنه مباح، وأنه

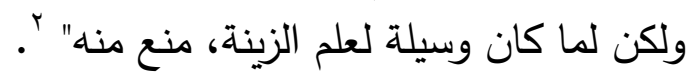
الأدلة من السنة: لمان

1- ق قال صلى الله عليه وسلم: " الحلال بيّن

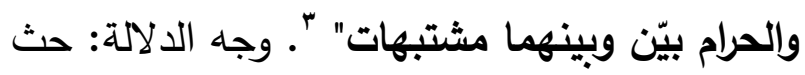

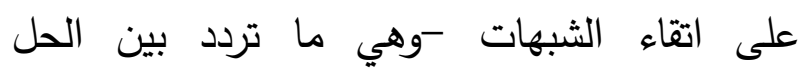
والحرمة" - سدا لذريعة الوقوع في المحرمات . r- قال صلى الله عليه وسلم: " دع ما يريبك

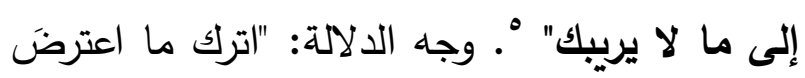

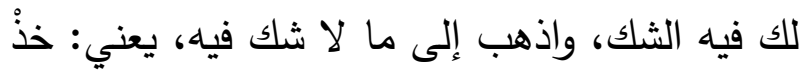

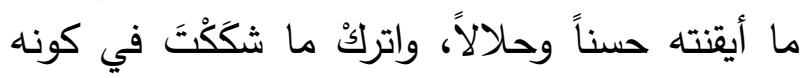

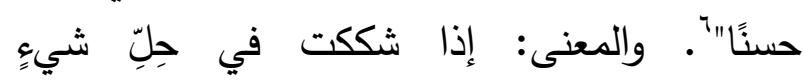

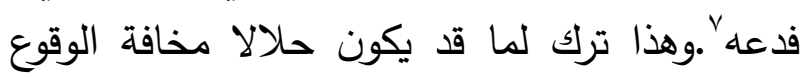

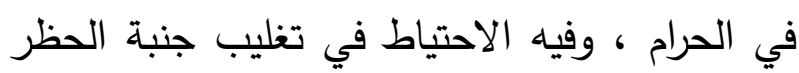
على الإباحة.

r- قال صلى الإباله الله عليه وسلم:" لايجمع بين المرأة وعمتها ولا بين المرأة وخالتها" وقال: "إنكن ولئ

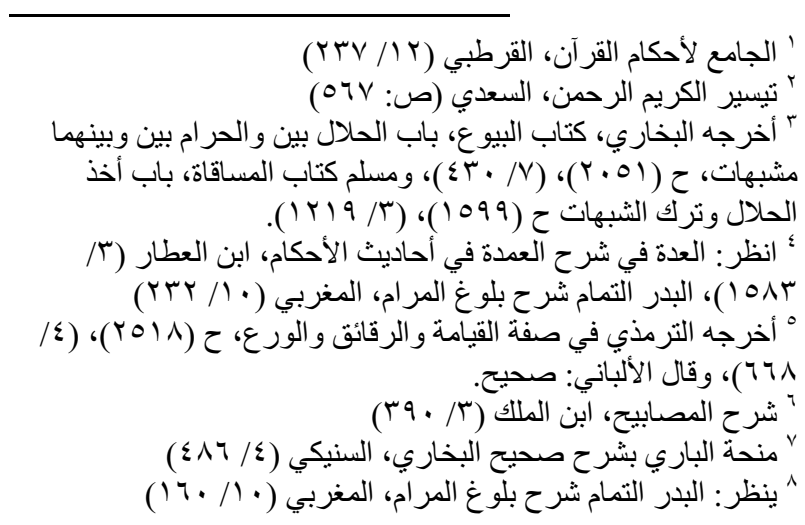




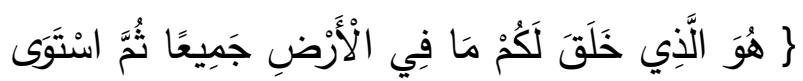

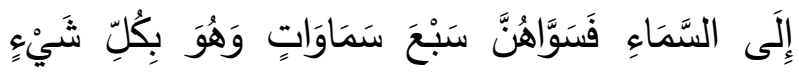

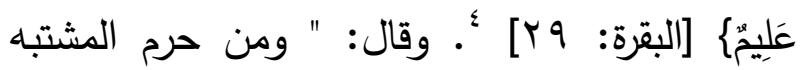
وأفتى بذلك وحكم به على الناس، فقد زاد في الدين ما لم يأذن به الله تعالى، وخالف النبي صلى صلى الله

$$
\text { عليه و سلم " لمادن لبه }
$$

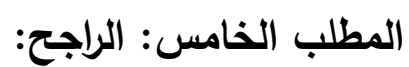

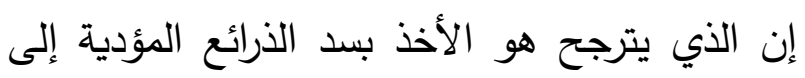

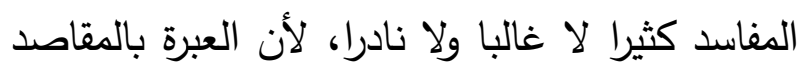

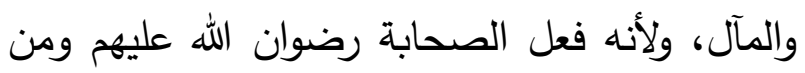
ذلك:

أن سعيد بن المسيب رضي الله عنه قال: غرَّب

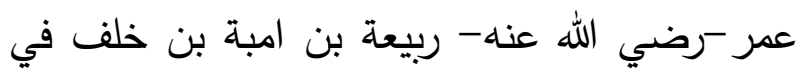

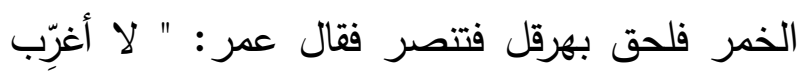

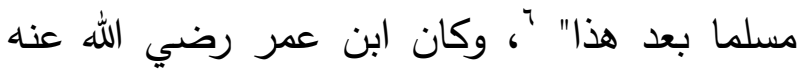

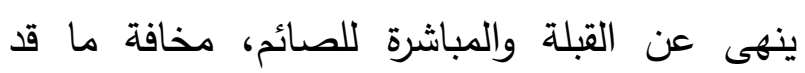
يحدث منهما'، ونقل ابن عطية رحمه الله أن عمر النه

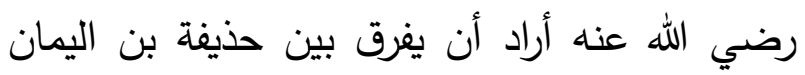

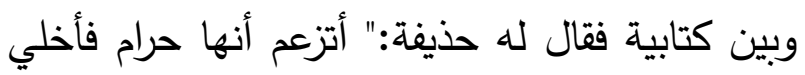

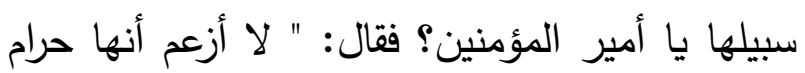

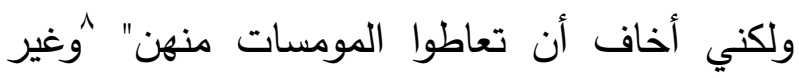

\footnotetext{
؛ الإحكام في أصول الأحكام، ابن حزم (1/ • • (1) )

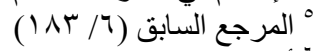

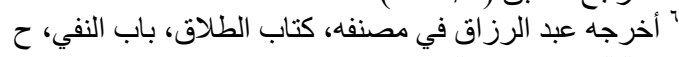
(r)

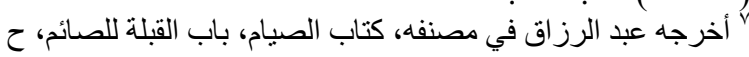

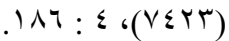

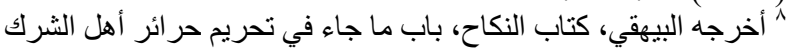

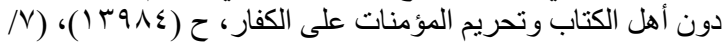

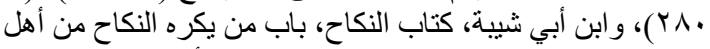

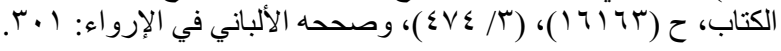

1- عن معاذ بن جبل رضي الله عنه: أن رسول

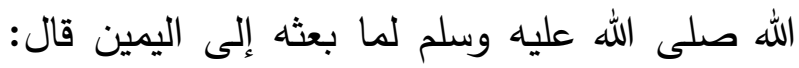

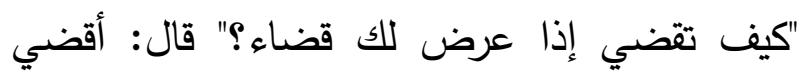
بكتاب الله قال: "فإن لم تجد في كتاب الله؟" قال:

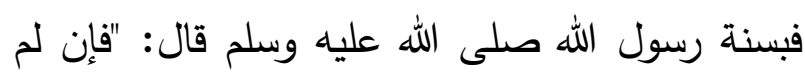
تجد في سنة رسول الله؟" قال: أجتهد رأيي ولا آلو قال: فضرب رسول الله صلى الله عليه وسلم على فلى رسول الله صدره وقال: "الحمد لله الذي وفق رسول رسول الله لما يرضى به رسول الله" '. وجه الدلالة: ذكر وله

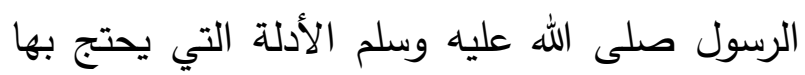

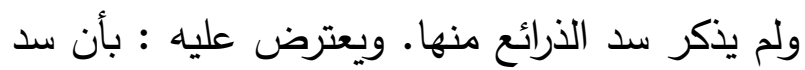

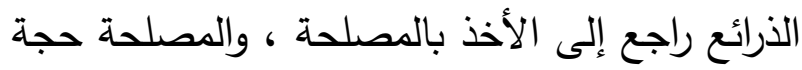

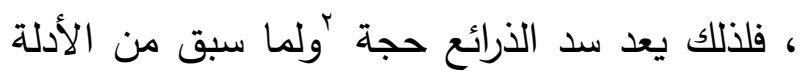
التي تتص على حجيته. r- قال صلى الله عليه وسلم: " الحلال بين الحئه والحرام بين وبينهما أمور مشتبهات" بـ، وجه الدلالة:

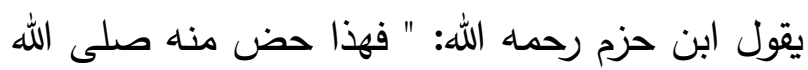

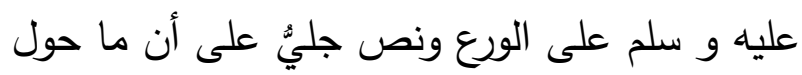

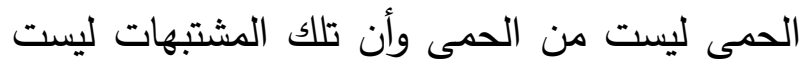
بيقين من الحرام وإذا لم تكن مما فصل من من الحرام

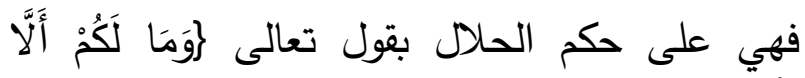

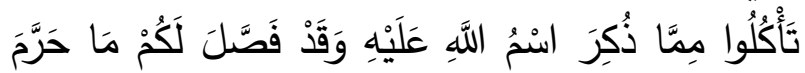

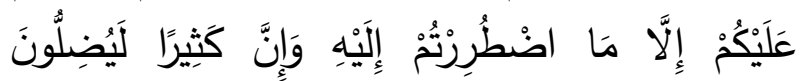

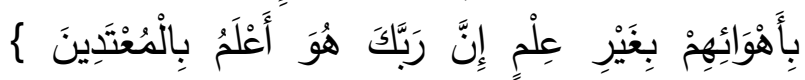

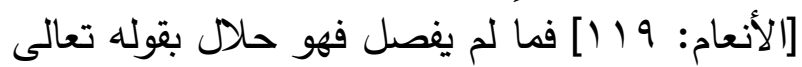

\footnotetext{
' (أخرجه أبو داود في سننه كتاب الأقضية، باب اجتهاد الرأي في القضاء،

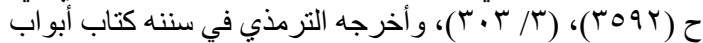

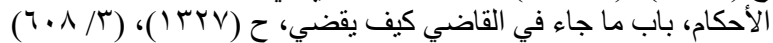

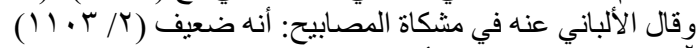

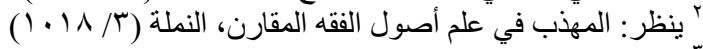
' سبث تخريجه (ص:V)
} 
ومحل البحث هوالزواج الذي تتوفر فيه الأركان والشروط وتسقط المرأة حقها في المبيت والنفقة والسكنى ويكون معلنا. المطلب الثاني: حكم المسألة: اختلف الفقهاء في دئن حكمه إلى خمسة أقوال: القول الأول: الإباحة لكنه خلاف الأولى .

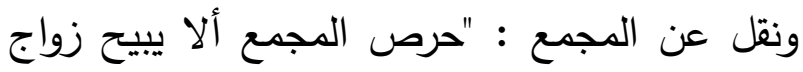
معينا باسمه؛ لأن هذا مما تختلف صوره وحالاته

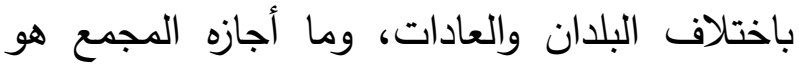
صورة محددة وهي: إبرام عقد زواج تتنازل فيه المرأة عن السكن والنفقة والقسم أو بعض منها، وترضى زئ بأن يأتيها الرجل إلى دارها في أي وقت شاء من ليل

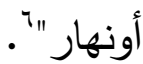

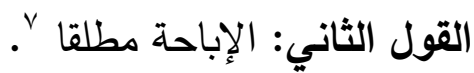

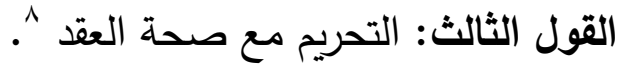

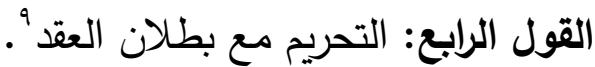

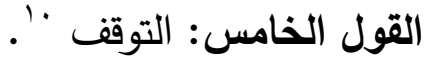

مجلة المجمع الفقهي الإسلامي السنة التاسعة عشرة، العدد الثاني

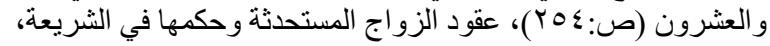
و وبة الزحيلي (ص: (1))، عقود الزوراج المستحدثة وحكمها في الثريعة،

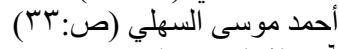
" مجلة المجمع الفقهي الإسلامي السنة التاسعة عشرة، العدد الثاني

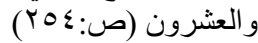

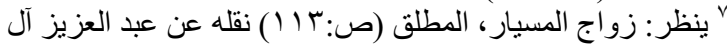

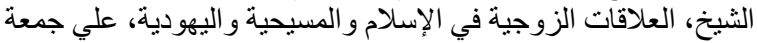

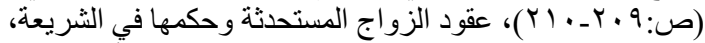

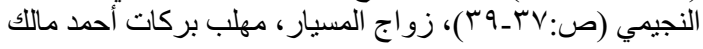
(ص) ^ينظر : أسامة بن عمر بن سليمان الأثقر ، مستجدات فقهية في قضايا

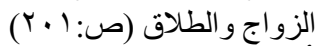

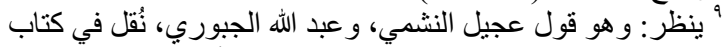

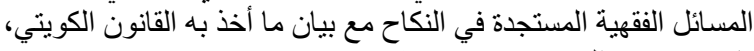

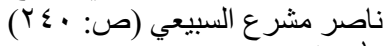

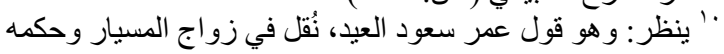

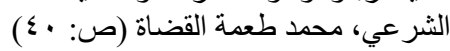

المبحث الثاني: زواج المسيار المطلب الأول: تصوير النازلة: هو نكاح تتوافر فيه الأركان والثروط خال من الثنال

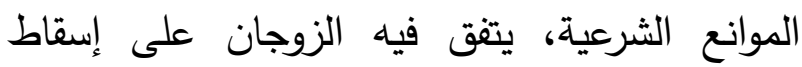
بعض الحقوق كالسكن والنفقة والمبيت ' لـ سمي لاني

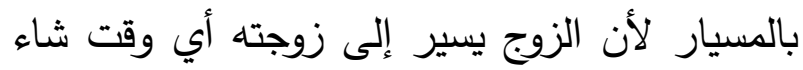

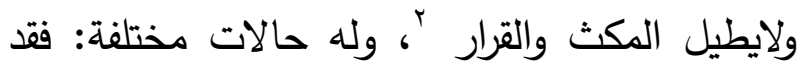

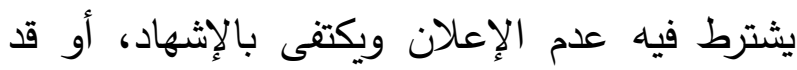

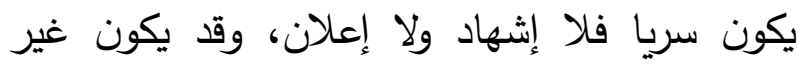

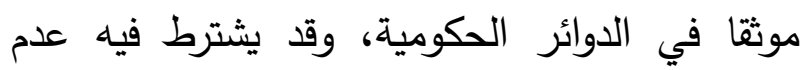
الإنجاب، وقد يشترط فيه ألا ترثه بعد موته، أو أو يشترط عدم المهر، أو أن تنفق عليه، ويختلف الحكم

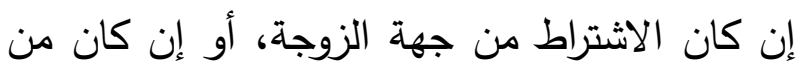

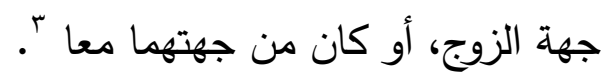
من صوره: 1- أن تتنازل المرأة عن النفقة والسكن والإنجاب فتتفق على نفسها وتسكن في بيت أهلها أو بيتها.

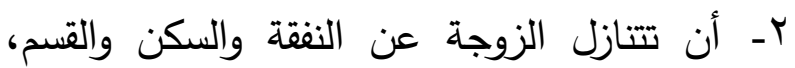
لكن لا تتنازل عن الإنجاب.

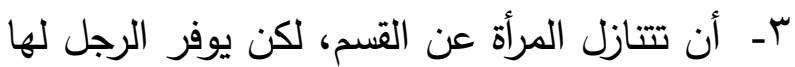

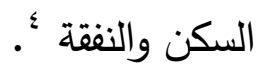

' ينظر: عقود الزواج المستحثثة وحكمها في الثريعة، محمد النجيمي (ص)

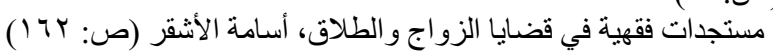

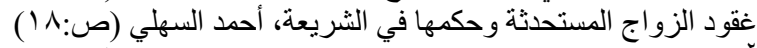
' زواج المبيار دراسة فقهية و اجتماعية نقاية، محمد فالح مطلق (ص: " براجع: المعيار في بيان أقسام نكاح المسيار، محمد القحطاني

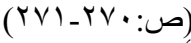

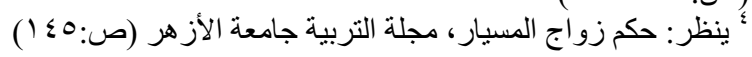


المبيت، وإسقاط حق النفقة؛ وهذا يبطل العقد والثرط استدل القائلون بالتوقف بتعارض المصالح

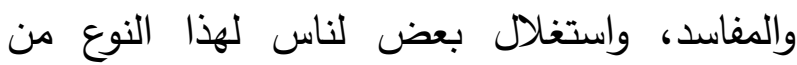
الزواج وتجاوزهم الحد الثرعي فيه حيث أصبح

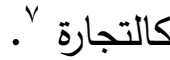
المطلب الثالث: أثر قاعدة سد الذرائع على زواج

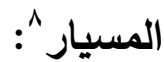
اختلف العلماء في أثر مآلات الأفعال على الحكم

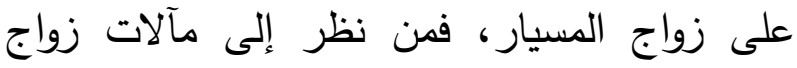

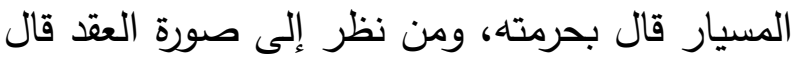

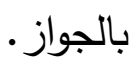
يقول الثاطبي رحمه الله :" النظر في مآلات الأفعال معتبر مقصود شرعا كانت الأفعال موافقة أو مخالفة، وذلك أن المجتهد لا يحكم على فعل من الأفعال الصادرة عن المكلفين بالإقدام أو بالإحجام إلا بعد الإل الإل نظره إلى ما يؤول إليه ذلك الفعل، مشروعا لمصلحة

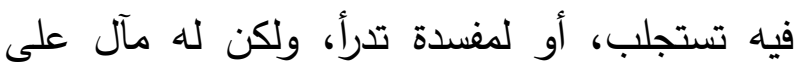
خلاف ما قصد فيه، وقد يكون غير مشروع لمفسدة

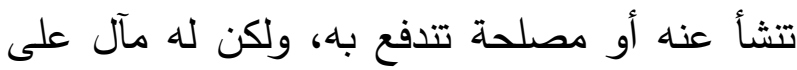

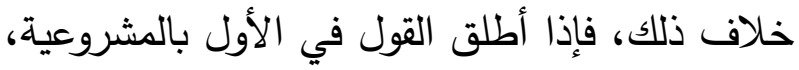

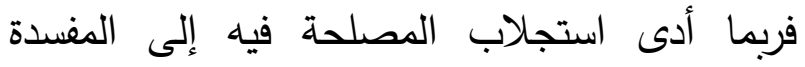

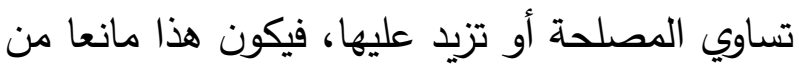

ينظر : المسائل الفقهية المستجدة في النكاح، ناصر مشر ع السبيعي (ص:

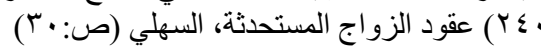

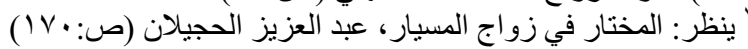

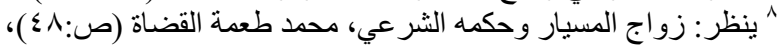

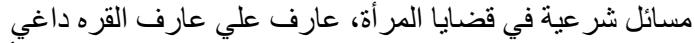

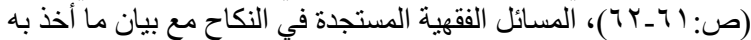

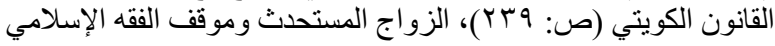

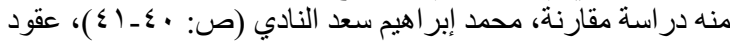

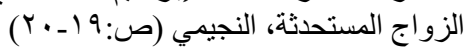

استدل القائلون بالإباحة مع كونه خلاف الأولى عن

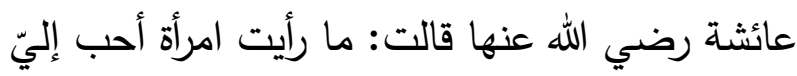

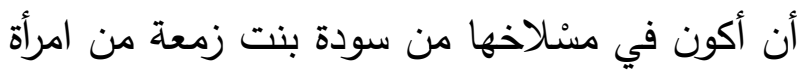

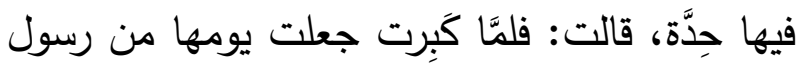

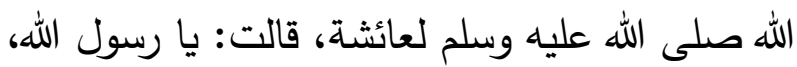

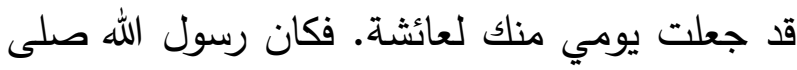

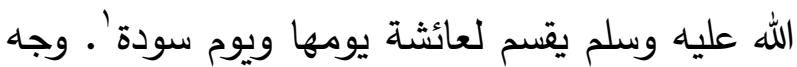
الاستدلال من الحديث: إقرار النبي صلى الله عليه وسلم لإسقاط زوجته سودة رضي الله عنها حقها في

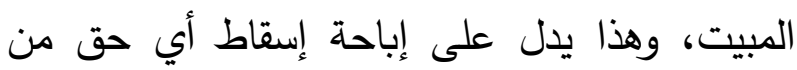

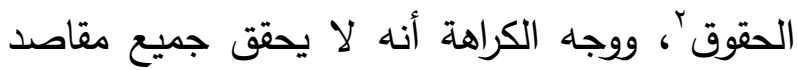

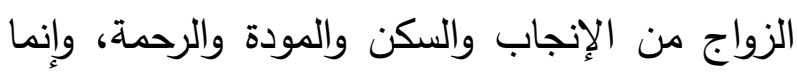
يقتصر على المتعة والأنس الّاب

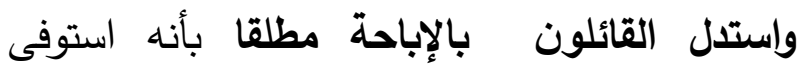
الأركان والثروط وخلا من الموانع، فالأصل صحته بالئه ولا يضر الاتفاق على قضية النفقة والمبيت والقسم

واستدل القائلون بالتحريم مع صحة العقد أنه ذريعة

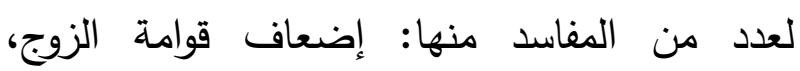

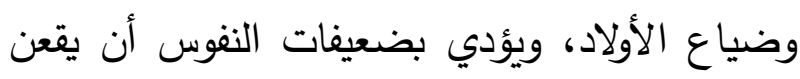

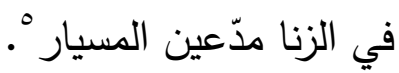
واستدل القائلون بالتحريم مع بطلان العقد بأن فيه

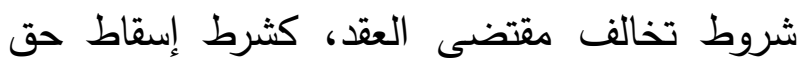

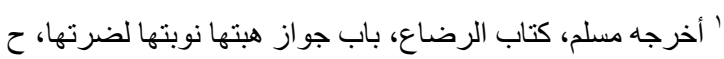

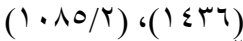
ك بيظر : المسائل الفقهية المستجدة في النكاح مع بيان ما أخذ به القانون

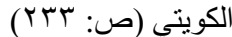

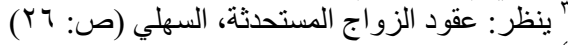

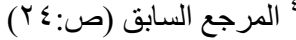
ه ينظر : مسائل شر عية في قضايا المر أة، عارف علي عارف القره داغي 
وقد يعترض عليه : بأن هذه المفاسد ليست مقتصرة

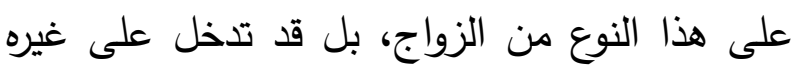
وعلى الزواج المعتاد؛. ويجاب عن هذا الاعتراض: بأن واقع زواج المسيار

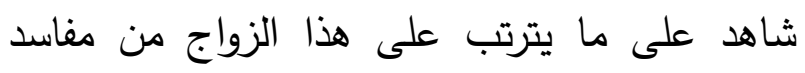
تتعلق بالمرأة وبالأطفال الذين هم نتاج هذا على الزواج.

\section{الخاتمة}

الحمد لله والصلاة والسلام على رسول الله، أما بعد: فإنه بعد البحث والنظر في قاعدة سد الذرائع نجد

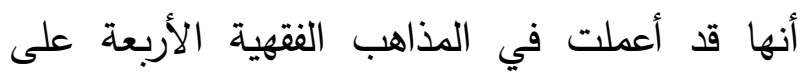

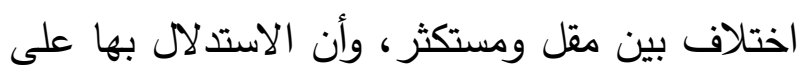

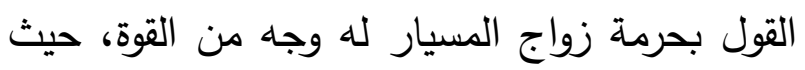

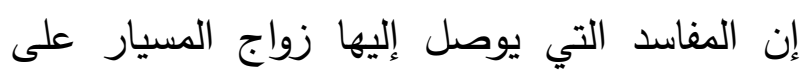

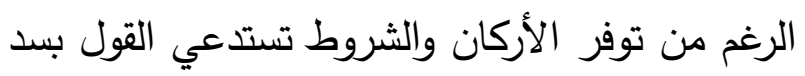

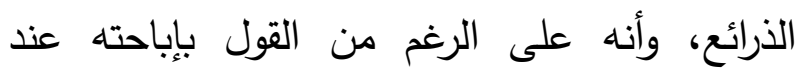
البعض إلا أن هذه الإباحة على خلاف الرغ من الأولى كونه

لايحقق المقاصد من الزواج وتترتب عليه مفاسد.

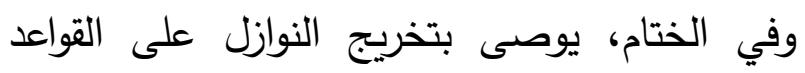

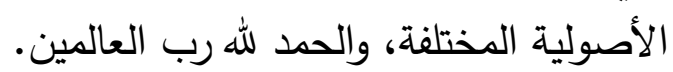

\section{فهرس المراجع}

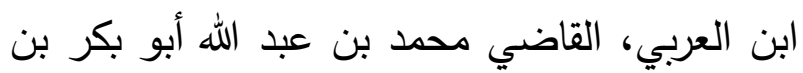

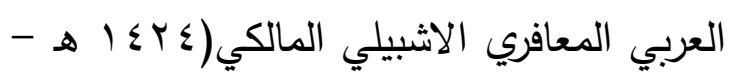

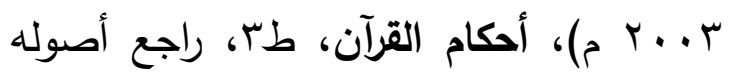

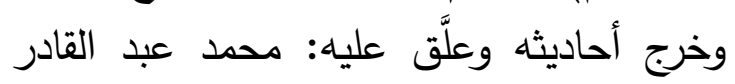
عطا، بيروت: لبنان

و ينظر : مجلة المجمع الفقهي الإسلامي، السنة التاسعة عشرة، العدد الثاني

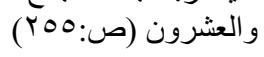

إطلاق القول بالمشروعية، وكذلك إذا أطلق القول في الثاني بعدم مشروعية ربما أدى استدفاع المفسدة إلى إلى إلى إلى إلى إلى

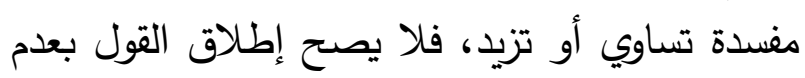
المشروعية وهو مجال للمجتهد صعب المورد، إلا أنه فله عذب المذاق محمود الغب، جار على ملى مقاصد الشريعة" ' الثدي

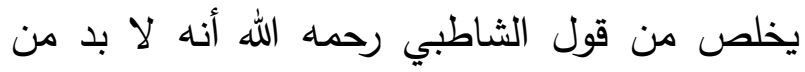
النظر فيما تؤول إليه هذه الأنكحة معتبر ومقصود شرعا بغض النظر عن صحة أركانها وشروطها، فلابد من النظر في مآلات هذه الأنكحة حتى يكون آركانها وشتوطيا، الحكم عليها فرع عن تصورها. "إن المقصود بسد الذرائع تحريم بعض الهورها.

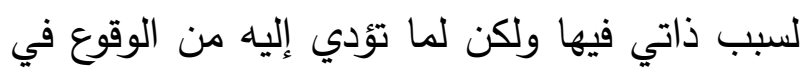

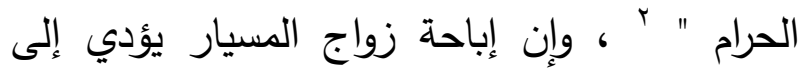

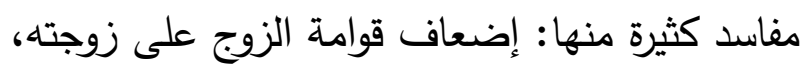

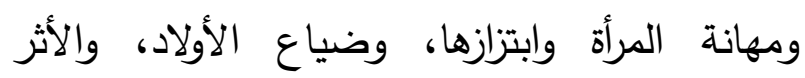
النفسي على الزوجة حال الإهمال والاكتفاء بارواء الرجل رغباته، وكثرة الطلاق لخفة المؤونة، ولأن أسباب تحصيل المودة والرحمة من القسم والسكن غير متوافرة في زواج المسيار بعكس الزواج العاديّ فيقضي هذا القول بتحريم هذا الزواج أخذا بمبدأ سد

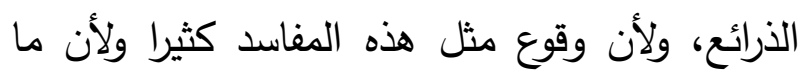

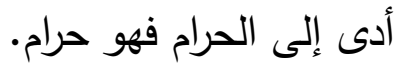




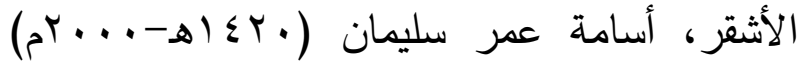

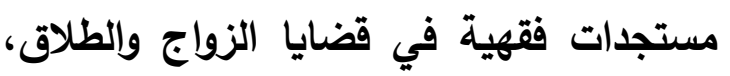
عمان: الأردن: دار النفائس

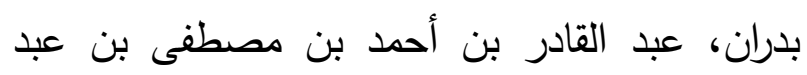

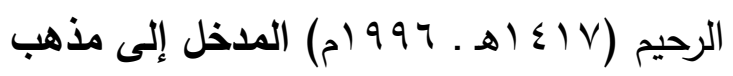
الإمام أحمد لابن بدران، تحقيق: محمد أمين الهن المدان

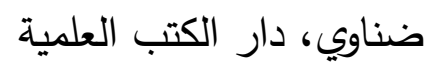

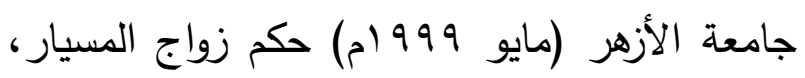

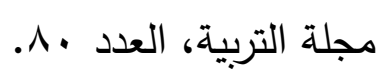

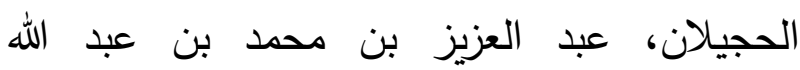

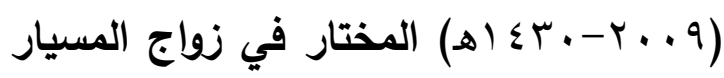
دراسة فقهية مقارنة حديثة، عمان: دار صفاء لهاء الميار للنشر والتوزيع.

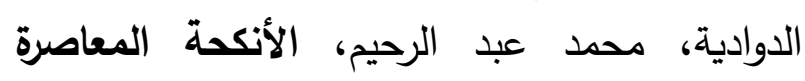

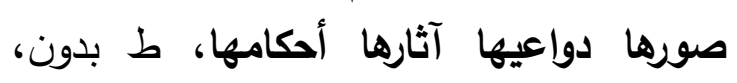
إشراف: أحمد العوضي، رسالة ماجستير من لنارها

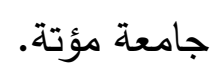

الرازي، زين الدين أبو عبد الله محمد بن أبي بكر بن أبن

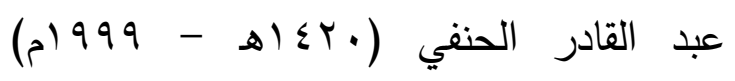
مختار الصحاح، طه، تحقيق: يوسف الثيخ الهن

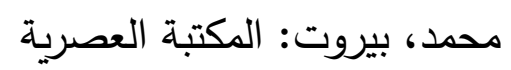
الزركشي: أبو عبد الله بدر الدين محمد بن عبد الله

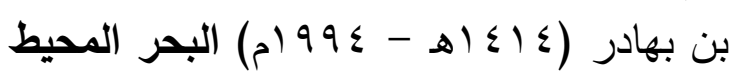
في أصول الفقه، دار الكتبي السبكي، تاج الدين عبد الوهاب بن تقي الفعه دان الدين

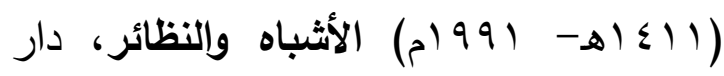
الكتب العلمية

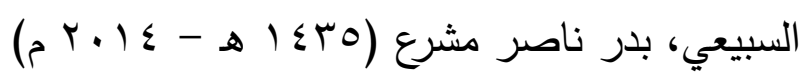
المسائل الفقهية المستجدة في النكاح مع بيان
ابن الملك، محمد بنُ عز الدينِ عبدِ اللطيف فِرِشْتَا

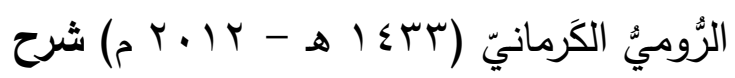

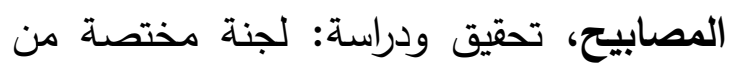

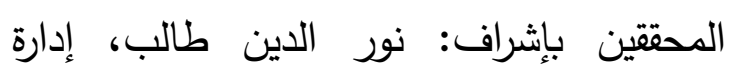
الثقافة الإسلامية ابن النجار، تقي الدين أبو البقاء محمد بن أحمد بن الإن

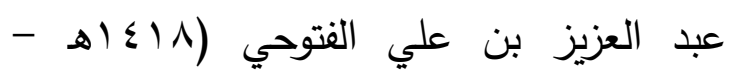
199V

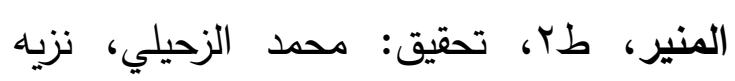
حماد، مكتبة العبيكان

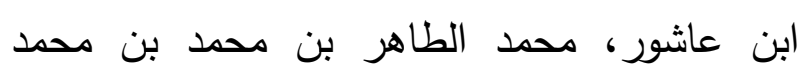

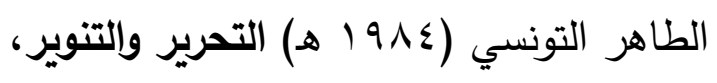
تونس: الدار التونسية للنشر ابن عطية، أبو محمد عبد الحق بن عطية الأندلسي لإني

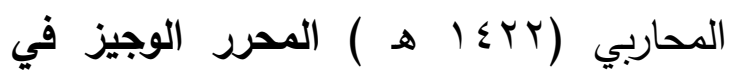

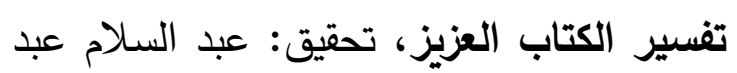
الثافي محمد، بيروت: دار الكتب العلمية

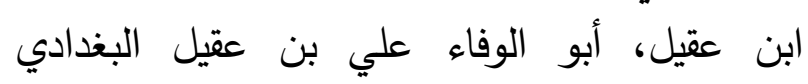

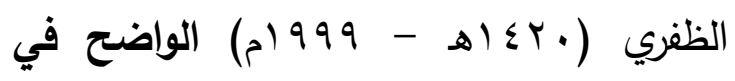
أصول الفقه، تحقيق: الدكتور عَبد الله بن عَبد الهُ

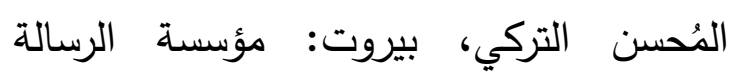
للطباعة والنشر والتوزيع. ابن فارس، أحمد بن فارس بن زكريا القزويني

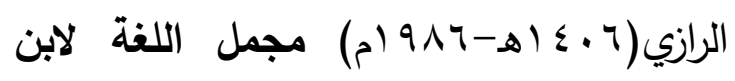
فارس، طץ، دراسة وتحقيق: زهير عبد المحسن سلطان، بيروت: مؤسسة الرسالة

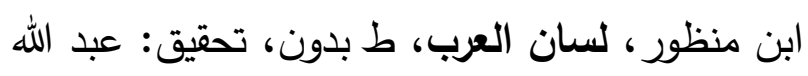

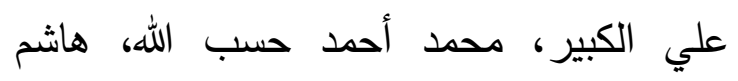
محمد الثاذلي، القاهرة: دار المعارف. لمثيز 
شرح مختصر الروضة، تحقيق: عبد الله بن عبد المحسن التركي، مؤسسة الرسالة.

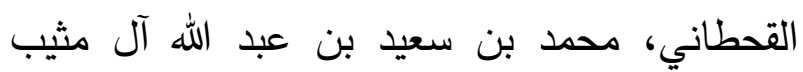
(رجب 11 إrم) المعيار في بيان أقسام نكاح

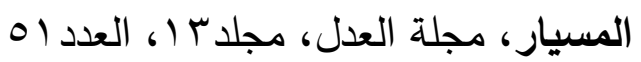

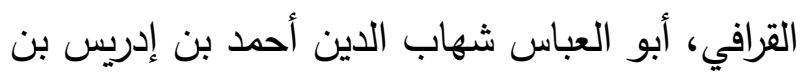

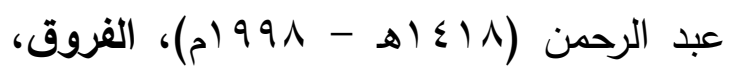

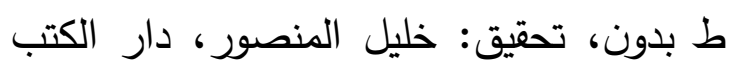
العلمية بانية

القرافي، أبو العباس شهاب الدين أحمد المالكي

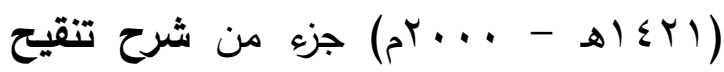
الفصول في علم الأصول، ط بدون، إعداد:

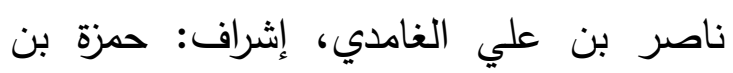
حسين الفعر، جامعة أم القرى.

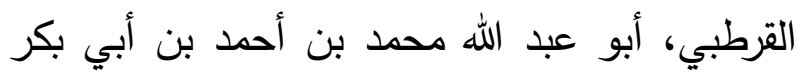

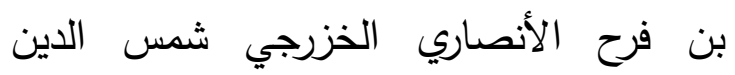

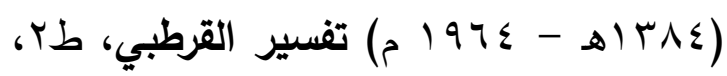
تحقيق: أحمد البردوني، إبراهيم أطفيش، القاهرة: دار الكتب المصرية العمدية القره داغي، عارف علي عارف، مسائل شرعية في قضايا المرأة، ط بدون، بيروت: لنان دار دار الكتب العلم

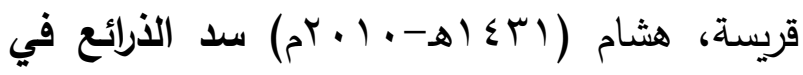

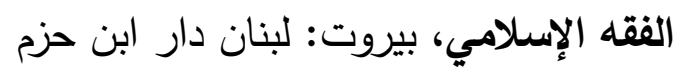

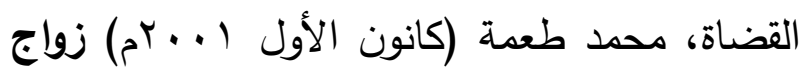
المسيار وحكمه الثرعي، الأردن: مجلة الزرقاء

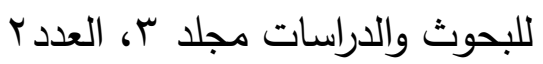

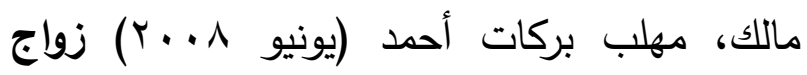
المسيار، ط بدون، السودان: مجلة المنبر . بوني
ما أخذ به القانون الكويتي، إشراف: فهد سعد

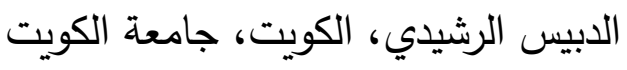

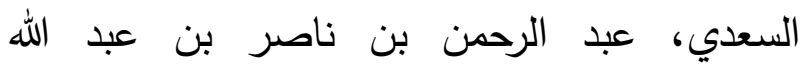

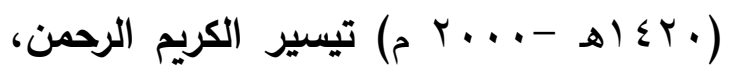

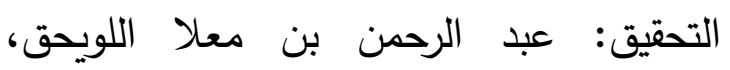
مؤسسة الرسالة

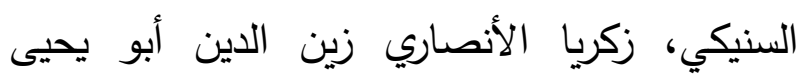

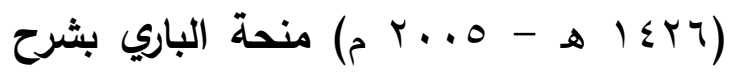
صحيح البخاري، اعتنى بتحقيقه والتعليق عليه:

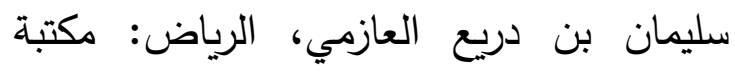
الرشد للنشر والتوزيع ديع التعان

السهلي، أحمد بن موسى، غقود الزواج المستحدثة وحكمها في الثريعة، ط بدون، الدورة الثامنة

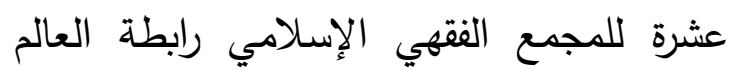
الإسـامي الثاطبي، إبراهيم بن موسى بن محمد اللخمي

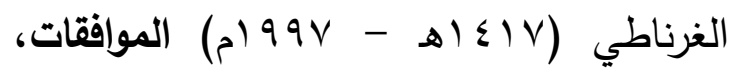

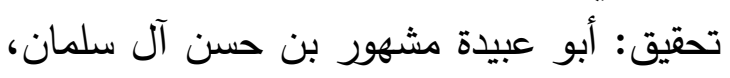
دار ابن عفان.

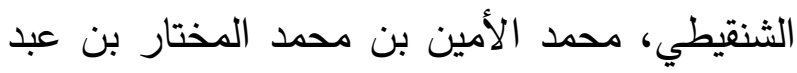
القادر الجكني (10 1 ألهـ - 1990 19 هـ) أضواء

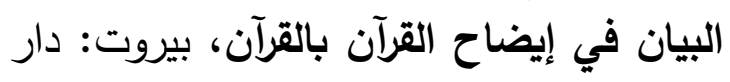
الفكر للطباعة والنشر والتوزيع

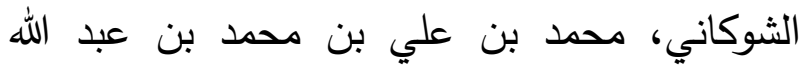

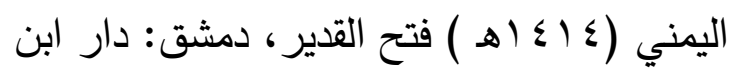

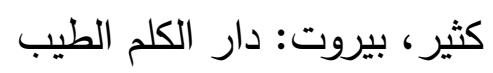

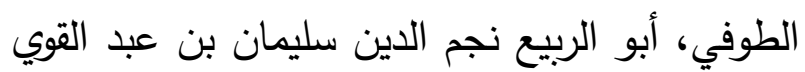

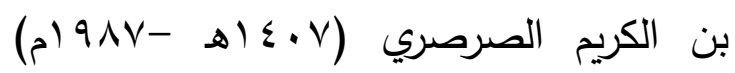


النجيمي، محمد بن يحيى بن حسن، عقود الزواج

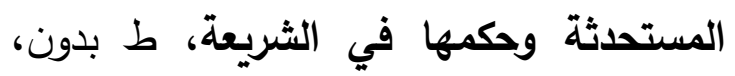

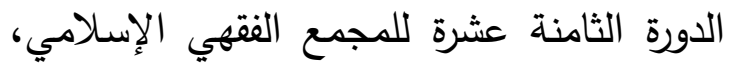
رابطة العالم الإسلامي فهرس الموضوعات: المقدمة ب-ب الإي المبحث الأول: قاعدة سد الذرائع ويشتمل على لى لى مطالب تحتوي ما يلي: معنى القاعدة، وتحرير محل

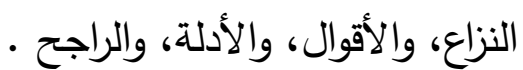
$q-\varepsilon$ المبحث الثاني: زواج المسيار ويشتمل على مطالب تحتوي ما يلي: تصوير النازلة، وحكم المسألة، وأثر مأثران قاعدة سد الذرائع على زواج المسيار .

$$
\text { Ir-q }
$$

الخاتمة: وستتضمن أهم النتائج والتوصيات.
المباركفوري، أبو الحسن عبيد الله (ع ـــ هـ،

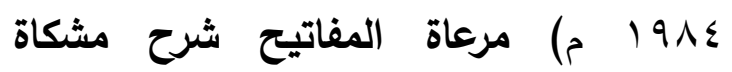
المصابيح، طس، نارس الهند: إدارة البحوث

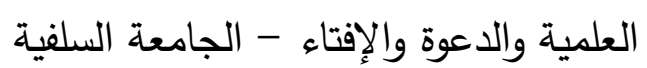

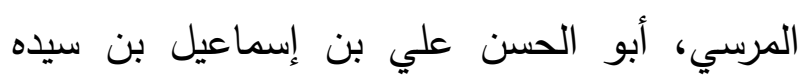

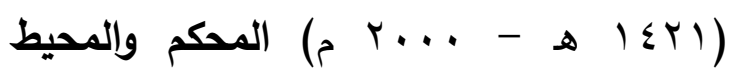
الأعظم، تحقيق: عبد الحميد هنداوي، بيروت:

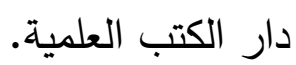

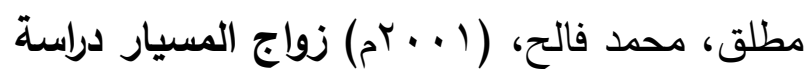

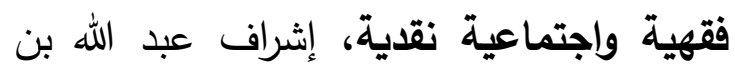
محمد الصالح، الأردن: رسالة ماجستير جامعة إنماف

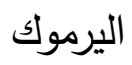

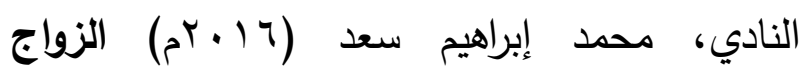
المستحدث وموقف الفقه الإسلامي منه دراسة مقارنة، الإسكندرية: مكتبة الوفاء القانونية. 


\title{
The impact of the rule of exclusion damages in misyar marriage
}

\author{
Roaa Talal Abdul Rahman Mhgob \\ Faculty of Arts and Humanities \\ Jeddah - Kingdom of Saudi Arabia
}

\begin{abstract}
In the Name of Allah, and all Allah's prayers and peace be upon His messenger, Muhammad (PBUH); As referring branches to Assets is an extremely significant topic in the formulation of the talent of jurisprudence, this current research papers is conducted under the title: Influence of the Prohibition of Evasive Legal Devices Rule on Misyar Marriage. The research paper consists of an introduction, two research sections, a conclusion and indexes. The introduction discusses the topic of the whole research, explaining its significance, research plan, methodology and previous studies conducted on such topic.

The first research section deals with the Prohibition of Evasive Legal Devices Rule including the meaning of such rule, explaining matters subject to dispute therein, quotes, evidences, preferable opinions.

The second research section discusses Misyar Marriage including illustration of relevant legal cases, their judgment and the influence of Prohibition of Evasive Legal Devices Rule on Misyar Marriage.
\end{abstract}

The conclusion includes the most crucial outcomes and recommendations reached. 